\title{
The Social and Economic Impacts of E-hailing Application in Malaysia: A Review
}

\author{
A.K.S Al-Shakhrit, K. A. Masri", C. P. Othman \\ College of Engineering, Universiti Malaysia Pahang, Lebuhraya Tun Razak, 26300 Gambang, Kuantan, Pahang, Malaysia
}

\begin{abstract}
E-hailing is a service that allows users to book a journey online and provides a platform for users to interact with E-hailing companies. E-hailing service in Malaysia was launched in January 2018. Growing population and rising migration from rural to urban areas have put a strain on quality of life for Malaysia's population. The service is available in Malaysia. It has so far had success. E-hailing services have become more popular than traditional taxis for a variety of reasons. Customers are likely to seek out these providers' services as long as they pay close attention to their needs, solicit feedback often, and improve the quality of the services they give. Mobile applications developed by e-hailing businesses have had a significant influence on the taxi industry and public transportation in the last few years. Experts examined the impact of e-Hailing services on consumers, drivers and the public economy. Economics service created a lot of work prospects for drivers. Taxi industry struggling to keep up with E-Hailing system which put it under threat, as it cuts in taxi industry's profits. All e-hailing drivers must now obtain Public Service Vehicle (PSV) permits, but they complained that the regulations were too strict. Many of these driverpartners used E-hailing as a method to earn supplemental money in addition to driving. In the next several years, the way people move around in cities is anticipated to alter drastically. The conventional marketplace is being replaced by the online transaction as a method of conducting business. E-hailing in Malaysia today, as an alternative to private and public transportation, may be summed up by pointing out its increasing use.
\end{abstract}

ARTICLE HISTORY

Received: $14^{\text {th }}$ July 2021

Revised: $27^{\text {th }}$ July 2021

Accepted: $05^{\text {th }}$ Aug 2021

\section{KEYWORDS}

E-hailing

Transportation Services

Accessibility

Social and Economic

\section{OVERVIEW}

Living in an urban environment has its drawbacks, including crowdedness and a lack of space. More and more indiv iduals are forced to share a limited amount of space. Traffic congestion is one of the tradeoffs in metropolitan quality of life [1].

Human life quality will improve and deteriorate as technology improves and economic growth continues to increase as an unavoidable tradeoff that occur between these two [2].

Growing population and rising migration from rural to urban areas have put a strain on the quality of life for Malays ia's population [3] Malaysia's population is expected to reach 32 million by the year 2019 and occupy a land area of $330,000 \mathrm{~km} 2$. A significant percentage of Malaysians own a car due to the country's expanding urban population and increasing family incomes, and Malaysia's Klang Valley had a relatively high percentage of personal automobile ownership in 2000: 84\% of the population. At the time, the Klang Valley's population represented 21\% of Malaysia's population that covers $2826 \mathrm{~km} 2$ area. As more individuals are able to afford cars, they will be less likely to use public transportations and more likely to own their own vehicles [4]. A growing proportion of cars are privately owned in the city due to both necessity and cost [3] [5] . Study of automobile ownership and driving behaviour shows that mobility is the most important factor in deciding whether to purchase and use a vehicle [6]. The environment and quality of life of urban people will be improved with an appropriate and functional public transportation and transit system in some metropolitan regions [7]. Malaysian cities continue to experience a steady increase in the number of cars on the road, and as a result, they considered launching electronic hailing services (E-hailing). Anyone may use their mobile phone or computer to hire a private taxi, vehicle, or a limousine to pick them up from where they are and take them to anywhere they wish to go with this service. When Uber was launched in 2009, it was the first e-hailing service worldwide, and it was launched in Malaysia in January 2014, as this service grew as other applications such as Grab, Dascee, and MyCar emerged. It took the prime minister's announcement to make the service legal, and he issued rules in 2017 since it primarily affects the taxi sector in Malaysia [8].

E-hailing services have become more popular than traditional taxis for a variety of reasons. First and foremost, ehailing is cost-effective. As expected, e-hailing service providers were engaged in a competitive environment, in which the consumer stands to profit most. The providers are trying to make the consumer more comfortable by decreasing the cost of travel, introducing additional amenities to make the consumer more comfortable, and offering free trips to loyal customers who are committed to them. Their consumers' requirements and demands have to be understood in order for the company to be successful.

Customers are likely to seek out these providers' services as long as they pay close attention to their needs, solicit feedback often, and improve the quality of the services they give. Brand loyalty and business advocacy were both 
enhanced by this strategy. The provider's services may no longer match the consumers' demands without constant attention and input, resulting in their frustration, and the consumer may consider this provider a loser in comparison to another provider whose services fit customer's needs and pay more attention [8]. Table 1 lists some of the e-hailing providers.

Table 1. List of e-hailing companies [3]

\begin{tabular}{|c|c|c|c|}
\hline & Name of app & Name of company & Website \\
\hline & & & \\
\hline 1 & Big Blue Customer & Big Blue Capital (M) Sdn Bhd & bigblue.my \\
\hline 2 & BitCar & BitCar Malaysia Sdn Bhd & gobitcar.com \\
\hline 3 & Che & My Leisure Tour \& Travel Sdn Bhd & \\
\hline 4 & Gioaz & Ideal Technology Advancement Sdn Bhd & ciaoz2u.com \\
\hline 5 & Dacsee & DMD Technology Sdn Bhd & dacsee.com \\
\hline 6 & Diffride & Diff Global Solutions Sdn Bhd & diffride.com.my \\
\hline 7 & DOB & DB Network Sdn Bhd & dob.com.my \\
\hline 8 & Drivegth WeweJourney & Global Transportation Network Sdn Bhd & \\
\hline 9 & Eazi Car & Eazi Car Sdn Bhd & eazicar.app \\
\hline 10 & Eevom & Eevom Sdn Bhd & eevom.com \\
\hline 11 & eLIMO & GoGlobal Empire Travel \& Tours Sdn Bhd & \\
\hline 12 & EzCab & EZCab Sdn Bhd & ezcab.com.my \\
\hline 13 & Faszz & Faszz Technology (M) Sdn Bhd & faszz.com \\
\hline 14 & Firecab & H2HEservices Sdn Bhd & Firecab (Google Play) \\
\hline 15 & Firstone & $\begin{array}{l}\text { Alam Aset Management \& Consultancy } \\
\text { Sdn Bhd }\end{array}$ & \\
\hline 16 & Frenzt & Wekaotim Sdn Bhd & frenzt.com \\
\hline 17 & Gabir Malaysia & Gabir E-hailing Holding & \\
\hline 18 & Get Car & Powerful Travel and Tours Sdn Bhd & \\
\hline 19 & GoJo & Asian Famous Tours \& Travel Sdn Bhd & \\
\hline 20 & Grab & Grabcar Sdn Bhd & wuw.grab.com \\
\hline 21 & I Cabbi & Robust Universal Sdn Bhd & \\
\hline 22 & Jomrides & Usga Malaysia Sdn Bhd & jomrides.com \\
\hline 23 & Kwikride & Kwikride Sdn Bhd & kwikride.com \\
\hline 24 & Linkz & Pure Ride Sdn Bhd & linkz.my \\
\hline 25 & Mann Go & Mann Ventures Sdn Bhd & \\
\hline 26 & Maxim & Aist Malaysia Sdn Bhd & taximaxim.com \\
\hline 27 & Mula & Mula Car (M) Sdn Bhd & mula2u.com \\
\hline 28 & MyCar & Platform Apps Sdn Bhd & mycar.asia \\
\hline 29 & MyGo & Sackz Exdusive Sdn Bhd & mygo.net.my \\
\hline 30 & My2SG & Travelers Tours Malaysia Sdn Bhd & my2sg.com \\
\hline 31 & Nuc & Neo Urban Consolidated Sdn Bhd & nuccar.com \\
\hline 32 & \begin{tabular}{|l|} 
PicknGo \\
\end{tabular} & Pick n Go Sdn Bhd & pickngo.my \\
\hline 33 & Pickup2u & Pick Up Holding & pickup2u.com \\
\hline 34 & Pisang & Tonggak Niaga Sdn Bhd & \\
\hline 35 & Riding Pink & Riding Pink & ridingpink.com \\
\hline 36 & Ridez & Vertec Technology Solution Sdn Bhd & ridezmy \\
\hline 37 & Taxi Go & Cab Mmobility Sdn Bhd & taxigo.com.my \\
\hline 38 & Tutucars & Tutucars Sdn Bhd & tutucars.com \\
\hline 39 & Texspo & Texspo Technology Sdn Bhd & \\
\hline 40 & Tune Travel & Tune Travel Sdn Bhd & tune.travel \\
\hline 41 & UNID & Cubiqsoft Sdn Bhd & cubiqsoft.com \\
\hline 42 & ZeppOn & Zepp On Sdn Bhd & wuw.thezepp.com \\
\hline
\end{tabular}

Based on information from the Land Public Transport Agency website on Oct 3

A theory for the relationship between subjective norms and behavioural intentions as well as existent attitudes was established. Both Ajzen and Fishbein (1975) named this theory the Theory of Reasoned Actions (TRA). People's conduct is impacted by attitudes, ideas, values, and personal opinions according to this theory. The importance of this concept for e-hailing services is clear, as providers will be able to assess the requirements and demands of the consumers in order to evaluate the services they give, and will be able to meet consumers' expectations and seek their satisfaction as a result of a thorough understanding of this theory. According to both Ajzen and Fishbein, the Theory of Planned Behavior (TPB) is an improvement on the prior theory of TRA. Behavioral control perception was cited as a predictive capacity. As a result of this theory, conduct is highly influenced by subjective standards, attitudes and perceived behavioral control. As well as public relations, marketing, and sustainability, researchers utilize both TRA and TPB to evaluate the people's intentions 
in order to utilize technology and information systems. Consumers' intentions to use and continue to use the e-hailing service are heavily impacted by their subjective standards and values. [9].

\section{SOCIAL IMPACT OF E-HAILING SERVICE}

Mobile applications developed by e-hailing businesses have had a significant influence on the taxi industry and public transportation in the last few years. It was for this reason that experts decided to examine the impact of e-hailing services on the public economy. This influence can be understood from three points of view:

1. The impact of e-hailing on the consumers.

2. The impact of e-hailing on drivers.

3. The impact of e-hailing on taxi industry.

The e-hailing services have had a significant influence on consumers, as they have offered them with a variety of options when it comes to private transportation. As long as the market is functioning effectively, e-hailing services will provide consumers the lowest costs and highest levels of comfort. Creating a rivalry between companies that provide the same service is most beneficial to the user, since it enhances the services that are already accessible. About $80 \%$ of Malaysians still prefer the e-hailing service over the traditional taxi service, according to recent research. E-hailing has a superior pricing scheme than taxis; as an example, taxis charge passengers not only for the distance travelled but also for the time spent during the trip, whereas DragCars charge passengers simply for the distance travelled, regardless of how much time is spent during the trip, therefore, e-hailing is preferred in traffic jams.

On the other hand, Uber and other e-hailing services do not raise the price of a ride during rush hours or late at night [10]. Uber's international E-hailing cars likewise have a number of development issues; $\mathrm{f}$ or example, consumer safety is not adequately protected, and the link between the network driver and the device is unclear. Problems such as swiping orders and driver pickup orders are poorly managed, and local norms and regulations are frequently in conflict. E-hailing platforms with limited populations find it difficult to create network effects, and their international development is not effectively integrated into local culture [11]. Consumers tend to choose e-hailing services over taxis that are simply available on the street because of their accessibility. It was shown in a 2017 survey by the Malaysian Public Transport Council how e-hailing firms outperformed taxi services in every category. It has a better booking approach, better service information, shorter waiting periods, etc. People enjoy using the e-hailing service due to its simplicity of booking. Customers of e-hailing businesses may also earn rewards by using their services, such as free trips. By creating a link, this method encourages consumers to prefer one particular service to all others [12]

For drivers, the e-hailing service created a lot of work prospects. These flexible work opportunities are in high demand in Malaysia. To improve their income, over 220,000 Malaysians who are now employed are willing to take on another job, according to the Department of Statistics (DOS). This shows how popular e-hailing services are as a secondary source of income and part time job, according to the Ministry of Transport. The e-hailing firms' policies reduced the waiting time for consumers, which led to a rise in the number of trips a driver does in a day. In other words, this strategy increased the total productivity of drivers, therefore boosting their income [3]. A detrimental impact was also felt by the taxi sector with the introduction of the e-hailing service Even with the same profit margins, taxi services are struggling to keep up with e-hailing services. e-hailing is a one-unit operation, managed and controlled by a single mind, and choices are made for the advantage of the entire provider, which is why taxis are unable to keep up with it. The taxi business, on the other hand, does not have such a system, and b ecause of this, it is understandable that the e-hailing system severely impacts the taxi industry [13].

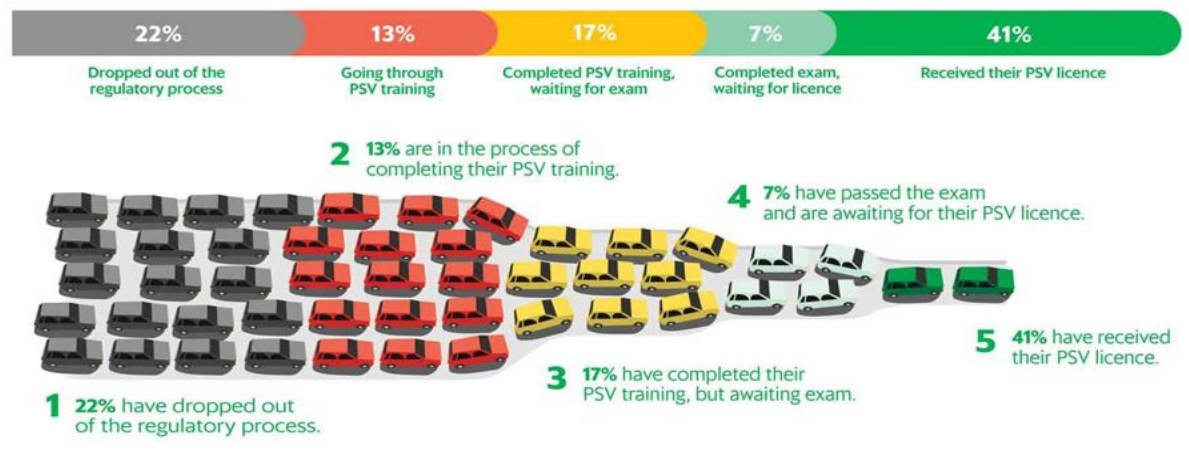

Figure 1: One of e-hailing companies vision [13]

All e-hailing drivers must now obtain Public Service Vehicle (PSV) permits, but they complained that the regulations were too strict. As seen in Figure 1, about $22 \%$ of formerly active driver-partners have abandoned e-hailing due to the time required to obtain their PSV licenses. Additionally, many of these driver-partners used E-hailing as a method to earn 
supplemental money in addition to driving. Better news is that $41 \%$ of drivers using e- hailing services currently possess a valid driver's license, while the remaining 7\% are still awaiting their licenses. The rest (17\%) are awaiting the paperbased exams.

\section{ECONOMIC IMPACT OF E-HAILING SERVICE}

Human mobility has been shown to be influenced by the number of predecessors and antecedents, such as the number of sites between destinations and distances [14]. Due to a lack of resources to monitor the time-resolved location of persons, despite the fact that research on human mobility have been conducted, our knowledge of the fundamental principles governing human motion remains restricted [5]. Assuming that human movement is spontaneous, [15] claims that it cannot be measured. In terms of both time and space, human trajectories are highly predictable, with timeindependent features, trip distance, and the chance of returning to a few regularly frequented locations [16]

A frequented location's mode of transportation depends on the information provided above. A single spatial probability distribution collapses individual journey designs, demonstrating that individuals adopt unambiguous and repetitive patterns regardless of their travel history [17]. In the next several years, the way people move around in cities is anticipated to alter drastically [18]. It's mostly because cities are using contemporary technology and digitalization as a way to adapt to changing conditions. Unprecedented levels of technology have been incorporated into daily life thanks to the Internet [19].

This new era in trade and business has been ushered in by the internet and other network-based technologies. Among the most notable beneficiaries of this ICT growth, for instance, is the Sharing Economy [15]. Consumers who trade access to products and services through internet platforms are engaging in what's known as collaborative consumption. The conventional marketplace is being replaced by the online transaction as a method of conducting business. If you're unfamiliar with the term, it's also known as ride sourcing in other countries. [20] It connects drivers with clients that require services on short notice and have access to underused transportation, such as motor cars. Profit-driven enterprises build, operate, and administer an online platform that establishes the relationship.

Transportation Network Companies (TNCs) are companies that balance transportation demands. After Uber, another start-up quickly commercialized the concept of e-hailing. Only in 2018, Grab and GoJek contributed US\$ 3.3 billion to Indonesia's economy, a research by Universitas Indonesia found [21] Another research in Jakarta's central area employed convenience sampling to interview commuters and drivers of transport vehicles [22]. These commuters were surveyed by researchers, who paid surveyors to do so.

\section{CONCLUSION}

The relevance of e-hailing in Malaysia today, as an alternative to private and public transportation, may be summed up by pointing out its increasing use. The number of e-hailing businesses has risen to more than 20 . Each one of these firms is in direct competition with the other, offering a wide range of services that benefit both consumers and drivers. How the e-hailing service affects taxis and government laws are also discussed. In Malaysia's cities, this service may be beneficial to all parties with a little attention and effort.

\section{REFERENCES}

[1] P. Ashrap et al., "Discovery of a widespread metabolic pathway within and among phenolic xenobiotics," Proc. Natl. Acad. Sci. U. S. A., vol. 114, no. 23, pp. 6062-6067, 2017, doi: 10.1073/pnas.1700558114.

[2] F. H. Sukri, B. C. Chew, S. R. Hamid, and H. S. Loo, "Building a sustainable land public transportation at Ayer Keroh, Malacca: Perspective view from hang tuah jaya municipal council (HTJMC)," AIP Conf. Proc., vol. 1818, 2017, doi: 10.1063/1.4976917.

[3] A. S. Jais and A. Marzuki, "Urban mobility using e-hailing in the Historic City Of Melaka, Malaysia: Preliminary findings," Int. Conf. Built Environ. Dev. Ctries., no. November, pp. 21-23, 2018.

[4] R. N. R. Ariffin and R. K. Zahari, "The Challenges of Implementing Urban Transport Policy in the Klang Valley, Malaysia," Procedia Environ. Sci., vol. 17, pp. 469-477, 2013, doi: 10.1016/j.proenv.2013.02.061.

[5] M. C. González, C. A. Hidalgo, and A. L. Barabási, "Understanding individual human mobility patterns," Nature, vol. 453, no. 7196, pp. 779-782, 2008, doi: 10.1038/nature06958.

[6] A. S. Jais and A. Marzuki, "Urban Mobility Using E-Hailing in the Historic City of Melaka," Malaysia Prelim. Find., no. April 2019, 2018.

[7] Z. A. Bohari, S. Bachok, and M. M. Osman, "Improving the Quality of Public Transportation System: Application of Simulation Model for Passenger Movement," Procedia - Soc. Behav. Sci., vol. 153, pp. 542-552, 2014, doi: 10.1016/j.sbspro.2014.10.087.

[8] R. Tachet et al., "Scaling law of urban ride sharing," Sci. Rep., vol. 7, pp. 1-6, 2017, doi: 10.1038/srep42868.

[9] V. Arumugam, M. R. Ismail, and M. Joeharee, "A review and conceptual development of the factors influencing consumer intention towards E-hailing service in Malaysia," Int. J. Innov. Creat. Chang., vol. 11, no. 11, pp. 224-242, 2020.

[10] L. Todd and A. Amirullah, "E-hailing regulations : striking the right balance," no. November, 2018. 
[11] J. Wirtz and C. Tang, "Uber: Competing as Market Leader in the US versus Being a Distant Second in China," Serv. Mark., pp. 626-632, 2016, doi: 10.1142/9781944659028_0019.

[12] IMF, "2016 Article IV Consultation — press release; staff report; and statement by the executive director for Greece," Int. Monet. Fund, no. 17, pp. 1-90, 2017.

[13] R. Hughes and D. MacKenzie, "Transportation network company wait times in Greater Seattle, and relationship to socioeconomic indicators," J. Transp. Geogr., vol. 56, pp. 36-44, 2016, doi: 10.1016/j.jtrangeo.2016.08.014.

[14] A. Noulas, S. Scellato, R. Lambiotte, M. Pontil, and C. Mascolo, "A tale of many cities: Universal patterns in human urban mobility," PLoS One, vol. 7, no. 5, 2012, doi: 10.1371/journal.pone.0037027.

[15] C. Cristiano and M. Bertin, "Scoping the Sharing Economy: Origins, Definitions, Impact and Regulatory Issues," SSRN Electron. J., no. 01, p. 36, 2016.

[16] R. Jenal, H. Mohamed, S. A. Hanawi, N. Athirah, and N. M. Idros, "User satisfaction index of e-hailing services based on cocreation value,” J. Theor. Appl. Inf. Technol., vol. 99, no. 10, pp. 2445-2457, 2021.

[17] A. A. Thompson, M. A. Peteraf, A. J. Strickland III, and J. E. Gamble, Crafting and executing strategy 17th edition. 2018.

[18] S. F. P. Dato Musa, Brunei darussalam, a country profile. 2019.

[19] Y. Chen, W. Salmanian, and A. Akram, "User Acceptance in the Sharing Economy: An explanatory study of Transportation Network Companies in China based on UTAUT2," Mcis, 2017.

[20] S. Shaheen, "Mobility and the Sharing Economy:Potential To Overcome First-and Last-Mile Public Transit Connections," UC Berkley, vol. 15, no. 4, pp. 250-260, 2013, doi: 10.7922/G2862DN3.

[21] G. Ramizo Jr and C. Chotib, “The Social Impact of Ride-Hailing Technologies: The Experience of Passengers and Drivers in Jakarta," pp. 115-128, 2020, doi: 10.4108/eai.6-11-2019.2297263.

[22] R. M. Medeiros, F. Duarte, F. Achmad, and A. Jalali, "Merging ICT and informal transport in Jakarta's ojek system,” Transp. Plan. Technol., vol. 41, no. 3, pp. 336-352, 2018, doi: 10.1080/03081060.2018.1435465. 